\title{
Enhancement of the Anti-Corrosion Performance of Composite Epoxy Coatings in Presence of BTA-loaded Copper-Based Metal-Organic Frameworks
}

\author{
Di Yin ${ }^{1,2,3}$, Zongxue Yu ${ }^{1,2,3, *}$, Legang Chen ${ }^{1,2,3}$, Kunyao Cao ${ }^{1,2,3}$ \\ ${ }^{1}$ Southwest Petroleum University, School of Chemistry and Chemical Engineering, Chengdu, 610500, \\ China; \\ ${ }^{2}$ Oil \& Gas Field Applied Chemistry Key Laboratory of Sichuan Province, Southwest Petroleum \\ University, Chengdu, Sichuan 610500, PR China; \\ ${ }^{3}$ State Key Laboratory of Oil \& Gas Reservoir Geology and Exploitation, Southwest Petroleum \\ University, Chengdu, Sichuan 610500, PR China \\ *E-mail: haiqingy@163.com
}

doi: $10.20964 / 2019.05 .13$

Received: 8 November 2018 / Accepted: 6 January 2019 / Published: 10 April 2019

This study reports a new strategy for enhancing anti-corrosion properties of epoxy coatings. For this purpose, copper-based metal-organic frameworks $(\mathrm{Cu}-\mathrm{MOF})$ were applied as hosts of corrosion inhibitor (benzotriazole, BTA). The BTA-Cu-MOF was characterized using Infrared spectroscopy (FTIR), Thermogravimetric analysis (TG) and X-ray diffraction (XRD). Furthermore, the BTA loading in MOFs was determined by UV-vis and TGA. And MOFs were well dispersed in epoxy resin which was confirmed by SEM and XRD. Compared to the pure epoxy coatings, epoxy coating including BTA-Cu-MOF had greater radius of impedance arc via the electrochemical impedance spectroscopy (EIS) and higher water contact angle, which revealed the samples enhanced corrosion resistance of pure epoxy coatings. At the same time, the corrosion protection performance of epoxy coating with 2 wt\% BTA-Cu-MOF were preferable than other coatings.

Keywords: copper-based metal-organic frameworks (Cu-MOF), benzotriazole, epoxy coating, corrosion resistance

\section{$\underline{\text { FULL TEXT }}$}

(C) 2019 The Authors. Published by ESG (www.electrochemsci.org). This article is an open access article distributed under the terms and conditions of the Creative Commons Attribution license (http://creativecommons.org/licenses/by/4.0/). 